\title{
DIFFERENTIAL GENETIC STABILITY IN VINEYARDS OF THE CULTIVAR 'ITALY' (VITIS VINIFERA L.) CULTIVATED IN DIFFERENT REGIONS OF SOUTHERN AND SOUTHWESTERN BRAZIL
}

\author{
ESTABILIDADE GENÉTICA DIFERENCIAL EM PARREIRAIS DA CULTIVAR 'ITALY' (VITIS \\ VINIFERA L.) CULTIVADA NAS REGIÕES SUL E SUDESTE DO BRASIL
}

\author{
Silvia Helena Zequim Maia ${ }^{1}$, Sandra Aparecida de Oliveira-Collet ${ }^{2}$, Claudete Aparecida Mangolin ${ }^{2}$; Maria de \\ Fátima P.S. Machado ${ }^{2 *}$
}

\author{
${ }^{1}$ Postgraduate Program in Genetics and Breeding; e-mail: silvelena.bio@hotmail.com. \\ ${ }^{2}$ Department of Biotechnology, Genetics and Cell Biology, State University of Maringá, 87020-900 Maringá, PR, Brasil.
}

*corresponding author: Tel: +55 4430114681 , email: mfpsmachado@uem.br

(Received 15.12.2017. Accepted 22.05.2018)

SUMMARY

During more than 50 years the vegetative propagation has been the form of maintaining and multiplication of the cv. 'Italy' vineyards, a 'Bicane' $\mathrm{x}$ 'Muscat Hamburg' hybrid. In the current study, polymorphism in 17 microsatellite loci was used to evaluate the genetic stability at DNA level in vineyards of cv. 'Italy' planted in different regions of the states of Paraná and São Paulo, Brazil. Unchanged and equal allele frequency indicating genetic stability was reported in $47 \%$ of the microsatellite loci in vineyards of six localities, while allele frequency variation has been observed in Scu15vv, Udv44, Udv74, Udv96, Udv107, Udv108, Vvmd5, Vvmd6 and Vvs3 microsatellite loci. Alleles $U d v 96^{140}$ and $V v s 3^{448}$, detected in vines in only one of the vineyards, evidenced somatic mutations at molecular level in cv. 'Italy'. Genetic diversity, as result of changes in the allele frequencies in 53\% of microsatellite loci, was detected more frequently than somatic mutations due to new alleles. Polymorphism in microsatellite loci revealed different genetic stability in vineyards of cv. 'Italy' cultivated in six different Brazilian regions and indicated vineyards with less genetic stability as a possible source of somatic mutants, showing traits of agronomic interest with a potential to generate new cultivars.

\section{RESUMO}

Durante mais de 50 anos a propagação vegetativa tem sido a forma de manter e multiplicar vinhas da cultivar 'Italy', um híbrido entre as variedades 'Bicane' x 'Muscat Hamburg'. No presente estudo, o polimorfismo dectado em 17 loci de microssatélites permitiu avaliar a estabilidade genética do DNA em vinhas da cv. 'Italy' plantados em diferentes regiões dos estados do Paraná e São Paulo, Brasil. Frequências alélicas iguais e inalteradas, indicam estabilidade genética, tendo sido reportadas em $47 \%$ dos loci microssatélites nas vinhas de seis localidades, enquanto variações na frequência de alelos foram observadas nos loci Scu15vv, Udv44, Udv74, Udv96, Udv107, Udv108, Vvmd5, Vvmd6 e Vvs3. Os alelos $U d v 96^{140}$ e $V v s 3^{448}$, detectados em videiras de apenas uma vinha demonstraram mutações somáticas a nível molecular na cv. 'Italy'. A diversidade genética, como resultado de alterações na frequência dos alelos em $53 \%$ dos loci microssatélites foi mais frequente do que as mutações somáticas, devido ao surgimento de novos alelos. O polimorfismo encontrado nos loci microssatélites revelou diferente estabilidade genética nas vinhas da cv. 'Italy' cultivadas nas seis regiões brasileiras e indicou as vinhas com menor estabilidade genética como uma possível fonte de mutantes somáticos, mostrando características de interesse agronômico com potencial para gerar novas cultivares.

Key words: table grapes, clonal polymorphism, genetic divergence, genetic identity.

Palavras-chave: uvas de mesa, polimorfismo clonal, divergencia genética, identidade genética.

\section{INTRODUCTION}

In the vegetative propagation of grape cultivars, there are several natural mutations at gene level which are linked to skin coloration and which play a significant role in the diversification of grape cultivars (Walker et al., 2007). A somatic mutation occurring on one side branch of the cv. 'Italy' (VIVC 5582), grown in Santa Mariana, northeastern region of the state of Paraná, Brazil, originated the cv. 'Rubi' (VIVC 22689; Kishino and Mashima, 1980). Another somatic mutation occurring on one side branch of cv.

\section{6}

This is an Open Access article distributed under the terms of the Creative Commons Attribution License (http://creativecommons.org/licenses/by/4.0), which permits unrestricted use, distribution, and reproduction in any medium, provided the original work is properly cited. 
'Italy' grown in Floraí, northwestern region of the state of Paraná, Brazil, gave rise to cultivar 'Benitaka' (VIVC 19816; Sousa, 1996). Further, in 1991, one side branch of cv. 'Benitaka', propagated also in Floraí, caused the rise of cv. 'Brasil' (VIVC 19817). In 2006, one side branch of cultivar 'Brasil', propagated in Marialva, northwestern region of the state of Paraná, gave rise to cultivar 'Black Star' (Roberto et al., 2012, 2015, 2017). The cultivar 'Redmeire' also originated from one side branch of cultivar 'Italy' propagated in Marialva, PR Brazil. Differently of 'Italy', the 'Redmeire' fruits are longovally shaped, with medium length/width ratio of 1.73, purple coloration and delicate muscatel taste (Pires et al., 2003). Both 'Black Star' and 'Redmeire' cultivars emerged by somatic mutations of 'Brasil' and 'Italy' cultivars, respectively, are not yet cataloged on the Vitis International Variety Catalog (VIVC) database. Like this, for more than three decades, several somatic mutations in the genome of the cv. 'Italy' selected several phenotypes which generated at least five new cultivars ('Rubi', 'Benitaka', 'Redmeire', 'Brasil', 'Black Star') of fine table grapes.

The cv. 'Italy' ('Piróvano 65'), which gave rise to three different cultivars ('Rubi', 'Benitaka' and 'Redmeire'), is a hybrid from the cross between 'Bicane' $x$ 'Muscat Hamburg'. It was introduced in the state of São Paulo, Brazil, in 1927 and its culture started in the northeastern region of the state of Paraná (Marialva) in 1962 (Camargo, 1998). For more than fifty years the vegetative propagation has been the form of maintaining and multiplication of cv. 'Italy' vineyards. Consequently, somatic variation has been the primary source of genetic variation employed to produce new phenotypic features. At molecular level, isozymes were used to measure the genetic stability of the introduced cv. 'Italy' (Oliveira-Collet et al., 2005). The lack of allele variation in cv. 'Italy' and in the 'Rubi', 'Benitaka', and 'Brasil' cultivars would indicate apparent genetic stability during the cultivation period. However, high frequency of the null EST-3 carboxylesterase phenotype $(61.7 \%)$ suggested the occurrence of genetic variations within cv. 'Italy' and their derivatives (Orasmo et al., 2007). High level of polymorphism within and between the cultivars 'Italy', 'Rubi', 'Benitaka' and 'Brasil' (65.1\%) were detected by random amplified polymorphic DNA (RAPD) markers, contrasting the hypothesis that the four cultivars were genetically identical (Maia et al., 2009).

Results described by Orasmo et al. (2007) and Maia et al. (2009) indicate that the genetic diversity of cv. 'Italy' must be high for a cultivar that has been maintained by vegetative propagation, in contrast to genetic uniformity preliminarily described by Oliveira-Collet et al. (2005). The simple sequence repeats (SSR) of DNA in current study were employed to investigate the genetic stability at DNA level in vineyards of cv. 'Italy' maintained in different regions of the states of Paraná and São Paulo, Brazil. SSR markers, also known as microsatellites, proved to be efficient to characterize the genetic diversity between varieties of grapes since the 1990s (Thomas and Scott, 1993; Thomas et al., 1994; Sefc et al., 1999). Although several studies have demonstrated the ineffectiveness of microsatellites to detect genetic diversity within clone collections (Aradhya et al., 2003; Martínez et al., 2006; Pelsy et al., 2010; Emanuelli et al., 2013), microsatellite markers may reveal the level of somatic mutations occurring in vines of cv. 'Italy'.

Although mutations that generated the cultivars 'Rubi', 'Benitaka' and 'Redmeire' were described only in the region of Santa Mariana, Florai, and Marialva in the state of Paraná, Brazil, it is possible that not easily identified mutations by morphological characteristics may be occurring in vines of cv. 'Italy' grown in different regions of the country. A high occurrence of somatic mutations may indicate low genetic stability in vineyards of cv. 'Italy', while a low incidence of somatic mutations may indicate greater genetic stability. In addition, information on greater or lesser genetic identity of the vineyards of cv. 'Italy' may be useful for agricultural and cultural practices (nutrition, fertilization, pruning, thinning, among others) of vineyards since plants genetically divergent in a vineyard may respond differently to the same agricultural and cultural practices. Moreover, lesser genetic stability of the vineyards may stimulate greater investment in the search of promising somatic mutations to generate new cultivars. Current hypothesis analyzes whether polymorphism in microsatellite loci may reveal a differential genetic stability in vineyards of cv. 'Italy' cultivated in different regions of the states of Paraná and São Paulo, Brazil.

\section{MATERIAL AND METHODS}

\section{Samples of the cv. 'Italy' of Vitis vinifera}

DNA was extracted from 69 plants obtained from vineyards in two Brazilian states, namely, Marialva, Paiçandu and Urai in the state of Paraná, and in Jales, Pilar do Sul and São Miguel Arcanjo in the state of São Paulo (Figure 1). Partially expanded leaves without phytosanitary contaminants were collected in 7 to 15 plants in each vineyard. The samples were 
individually stored in labelled plastic screen bags to avoid the mixture of vineyards, maintained on ice (4 ${ }^{\circ} \mathrm{C}$ ) and transferred to the laboratory. The samples were frozen in liquid nitrogen and stored at $-80{ }^{\circ} \mathrm{C}$ until DNA extraction.

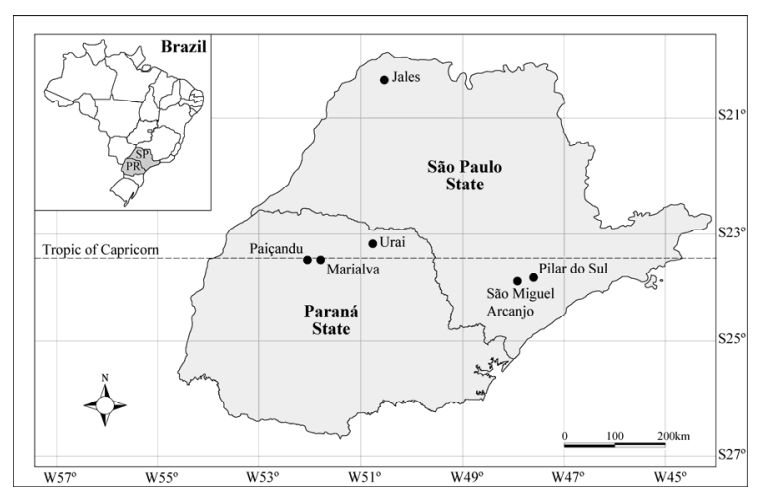

Figure 1. Distribution of the vineyards to form samples representative of cv. 'Italy' (Vitis vinifera) that has been maintained by vegetative propagation in two Brazilian states: Paraná (Marialva, Paiçandu and Urai) and São Paulo (Jales, Pilar do Sul and São Miguel Arcanjo).

Distribuição dos parreirais para formar as amostras representativas da cultivar 'Italy' (Vitis vinifera) que têm sido mantidas por propagação vegetativa nos dois estados Brasileiros: Paraná (Marialva, Paiçandu e Urai) e São Paulo (Jales, Pilar do Sul e São Miguel Arcanjo).

\section{DNA extraction}

DNA was extracted from leaf tissues following Thomas et al. (1994) with minor modifications. The modifications included the use of $100 \mathrm{mg}$ of leaves from individual plants replacing the $2.0 \mathrm{~g}$ of leaves used in the Thomas and Scott (1993) protocol. After DNA extraction, DNA quantity and quality were determined by $0.8 \%$ agar gel electrophoresis buffered with $1 \mathrm{x}$ TAE $(0.04 \mathrm{M}$ Tris-Acetate and $0.001 \mathrm{M}$ EDTA). A standard DNA ladder ( $\lambda$ phage, 50, 100 and $150 \mathrm{ng}$ ) was used as a marker. The gel was stained with $0.5 \mu \mathrm{g} \cdot \mathrm{m} / \mathrm{L}$ ethidium bromide, and the image was visualized with a Molecular Image LocCus L-PIX - HE (LocCus do BRASIL LTDA., São Paulo SP Brazil) with Picasa 3 software. UV quantification by visual comparison with known quantities of lambda DNA (Invitrogen) averaged between $15 \mathrm{ng} / \mu \mathrm{L}$ and $200 \mathrm{ng} / \mu \mathrm{L}$ per sample. After quantification, DNA samples were diluted in a 10 $\mathrm{ng} / \mu \mathrm{L}$ concentration.

\section{Primer selection and amplification reactions}

Thirty-eight SSR primers previously developed for Vitis vinifera were used with DNA samples to define the polymorphic primers. After screening the 38 SSR primers, a set of 17 polymorphic SSR primers, designed Vvs (Thomas and Scott, 1993), VVMD (Bowers et al., 1996, 1999), SCU (Scott et al., 2000), and UDV (Di Gaspero et al., 2005) (Table I), were selected for further analysis. Only 17 primers were polymorphic and used for all 69 plants.

Polymerase chain reaction (PCR) was performed with Techne TC-512 thermal cycler. Amplifications were performed by Touchdown PCR program (Don et al., 1991) using volumes of $20 \mu \mathrm{L}$ containing $25 \mathrm{ng}$ of genomic DNA, buffer reaction $(10 \mathrm{mM}$ Tris- $\mathrm{HCl} \mathrm{pH}$ 8.8), $2.0 \mathrm{mM}$ of $\mathrm{MgCl}_{2}, 0.1 \mathrm{mM}$ each of dATP, dGTP, dCTP, dTTP, $0.3 \mu \mathrm{M}$ of each primer (F and R primers), and 1 unit of Taq DNA polymerase (Invitrogen) and Milli-Q water to bring the reaction to the final volume. Electrophoresis was performed in a $4 \%$ MS-8 agar gel using $0.5 \times$ TBE buffer $(44.5 \mathrm{mM}$ Tris-borate and $1 \mathrm{mM}$ EDTA) at $60 \mathrm{~V}$, for $4 \mathrm{~h}$. After electrophoresis, the gels were stained with ethidium bromide at $0.5 \mu \mathrm{g} \cdot \mathrm{m} / \mathrm{L}$ and images were taken with a Molecular Image LocCUS L-PIX - HE using Picasa 3 software. The size of PCR fragments was determined with a 100 bp DNA Ladder (Invitrogen).

Polymorphisms from SSR loci were analyzed with PoPGENE 1.32 (Yeh et al., 1999) to estimate the average number of alleles per locus, the frequency of allele in each locus, the deficit of heterozygotes, and the genetic divergence between cv. 'Italy' vineyards from the two Brazilian states. Similarity matrix was computed with UPGMA (Sneath and Sokal, 1973), followed by Nei's clustering method (Nei, 1972), with resampling analysis, using 1000 replications. A dendrogram was constructed and drawn from a reference tree by R Development Core Team program (2013) using the adegenet package (Jombart, 2008).

\section{RESULTS AND DISCUSSION}

The analysis of 17 microsatellite loci in 69 samples of cv. 'Italy' from six vineyards cultivated in different regions of southern (Paraná state) and southeastern (São Paulo state) Brazil revealed three alleles in loci $U d v 96$ and $V v s 3$, and two alleles in loci Sculovv, Scu11vv, Scu15vv, Udv26, Udv32, Udv34, Udv40, $U d v 85, U d v 44, U d v 74, U d v 107, U d v 108, V v m d 5$, $V v m d 6, V v m d 7$ (Table II). Uniform and equal allele frequencies $(0.5000)$ were observed in $47 \%$ of the microsatellite loci in vines of the six localities (Marialva, Paiçandu, Uraí, Jales, Pilar do Sul and São Miguel Arcanjo). Unchanged and equal allele frequency indicated a genetic stability at the $S c u 10 v v$, Scu11vv, Udv26, Udv32, Udv34, Udv40,Udv85, and Vvmd7 loci (heterozygous $100 \%$ ) in vines of the six localities. Since cv. 'Italy' is the result of a cross 
between 'Bicane' and 'Moscat Hamburg' cultivars (Sousa, 1996), the original allele frequency in the hybrid maintained by vegetative propagation has remained unchanged for more than five decades (since 1962, in Marialva PR Brazil) in $47 \%$ of the microsatellite loci in vines of the six localities.

Table I

Nucleotide sequences of the microsatellite primers, simple sequence repeats of each primer, number of alleles detected by each primer in the cv. 'Italy' plants, and variation in allele size (bp) detected in the samples

Sequência de nucleotídeos dos primers microssatélites, sequências simples repetidas de cada primer, número de alelos detetados por cada primer nas plantas da cultivar 'Italy', e variação no tamanho dos alelos ( $\mathrm{pb}$ ) detetados nas amostras

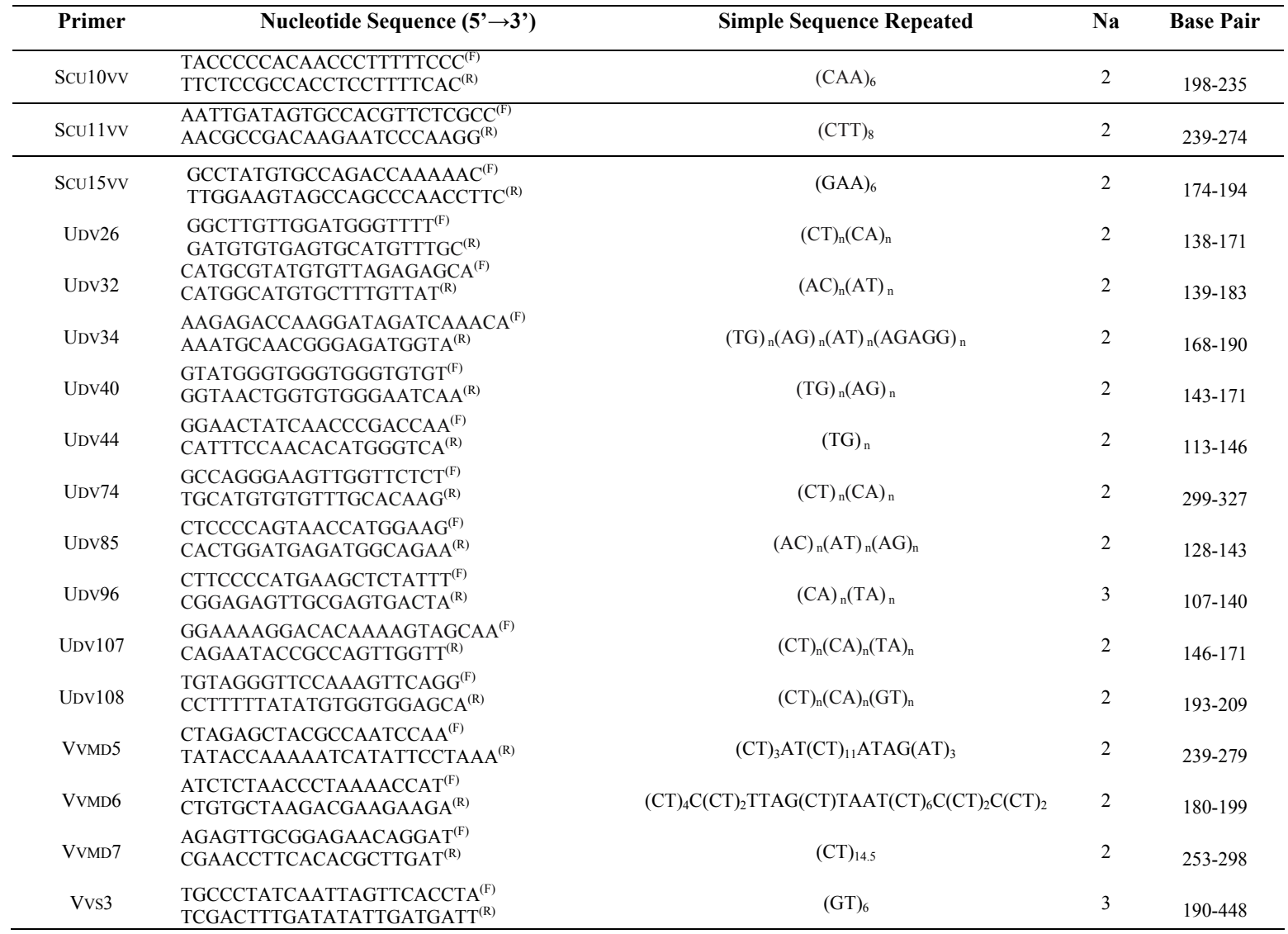

In contrast, allele frequency variation has been observed in Scu15vv, Udv44, Udv74, Udv96, Udv107, $U d v 108, V v m d 5, V v m d 6$, and Vvs3 microsatellite loci. For instance, the frequency of $U d v 96^{107}$ and $U d v 96^{115}$ alleles is different from 0.5000 and different in vines cultivated in the six regions of southern and southeastern Brazil (Table II). In addition, a third allele was detected at $U d v 96\left(U d v 96^{140}\right)$ and $V v s 3$ $\left(V v s 3^{448}\right)$ loci in a cv. 'Italy' vine from Paiçandu. Different allele frequencies in $S c u 15 v v, U d v 34$, Udv107, Udv108, Vvmd5 and Vvmd6 loci have conferred different level of mean heterozygosity for the vines of the six regions (Table III). Mean observed heterozygosity (Ho) was higher than mean expected heterozygosity $(\mathrm{He})$ rates and ranged from $\mathrm{Ho}=0.7000$ in vines of Paiçandu to $\mathrm{Ho}=0.9647$ in the vines of São Miguel Arcanjo. Highest He rates were estimated in the vines from Jales $(\mathrm{He}=0.4950)$ and São Miguel Arcanjo $(\mathrm{He}=0.4949)$, whereas the lowest rates were detected in vines from Urai $(\mathrm{He}=$ $0.4064)$ and Paiçandu $(\mathrm{He}=0.4085)$ (Table III). 
Table II

Allele frequencies in microsatellite loci of the 'Italy' cultivar (Vitis vinifera) from six localities: Jales (J1-J15), São Miguel Arcanjo (SM16SM30), Pilar do Sul (PS31-PS37), Uraí (U38-U52), Marialva (M53-M59), and Paiçandú (P60-P69)

Frequência de alelos nos locos microssatélites da cultivar 'Italy' das seis localidades: Jales (J1-J15), São Miguel Arcanjo (SM16-SM30), Pilar do Sul (PS31-PS37), Uraí (U38-U52), Marialva (M53-M59), e Paiçandú (P60-P69)

\begin{tabular}{|c|c|c|c|c|c|c|c|c|c|c|c|c|c|c|c|c|c|}
\hline Loci & $\begin{array}{c}\text { Scu10 } \\
v \mathrm{v}\end{array}$ & $\begin{array}{l}\text { Scu } \\
11 v v\end{array}$ & $\begin{array}{c}\text { Scu15 } \\
v v\end{array}$ & $\begin{array}{c}U d v 2 \\
6\end{array}$ & $\begin{array}{c}U d v 3 \\
2\end{array}$ & $\begin{array}{c}U d v 3 \\
4\end{array}$ & $\begin{array}{c}U d v \\
40\end{array}$ & $\begin{array}{c}U d v 4 \\
4\end{array}$ & $\begin{array}{c}U d v \\
74\end{array}$ & $\begin{array}{c}U d v \\
85\end{array}$ & $\begin{array}{c}U d v 9 \\
6\end{array}$ & $\begin{array}{c}\text { Udv1 } \\
07\end{array}$ & $\begin{array}{c}U d v 1 \\
08\end{array}$ & $\begin{array}{c}V v m \\
d 5\end{array}$ & $\begin{array}{c}\text { Vvm } \\
\text { d6 }\end{array}$ & $\begin{array}{c}\text { Vvm } \\
d 7\end{array}$ & Vvs3 \\
\hline J1 & $198 / 235$ & $239 / 274$ & $174 / 194$ & $138 / 171$ & $139 / 183$ & $168 / 190$ & $143 / 171$ & $113 / 146$ & $299 / 327$ & $128 / 143$ & $107 / 115$ & $146 / 146$ & $193 / 209$ & $239 / 279$ & $180 / 199$ & $253 / 298$ & $190 / 218$ \\
\hline & & 9/274 & $174 / 194$ & $8 / 171$ & 39/183 & $68 / 190$ & $43 / 171$ & $113 / 146$ & $9 / 327$ & $128 / 143$ & & $46 / 171$ & $193 / 209$ & & $80 / 199$ & & $190 / 218$ \\
\hline & $8 / 235$ & $9 / 274$ & $74 / 194$ & $38 / 171$ & $39 / 183$ & $68 / 190$ & $43 / 171$ & $113 / 146$ & 299/327 & $128 / 143$ & $107 / 115$ & $46 / 146$ & $193 / 209$ & $239 / 279$ & $80 / 199$ & $53 / 298$ & $90 / 218$ \\
\hline & $8 / 235$ & $39 / 274$ & 74/194 & $138 / 171$ & $139 / 183$ & $168 / 190$ & $143 / 171$ & $113 / 146$ & $299 / 327$ & $128 / 143$ & $107 / 115$ & $146 / 171$ & $193 / 209$ & $239 / 279$ & $180 / 199$ & $253 / 298$ & $190 / 218$ \\
\hline & & $39 / 274$ & 74/194 & $138 / 171$ & $39 / 183$ & $68 / 190$ & $43 / 171$ & $113 / 146$ & $299 / 327$ & $128 / 143$ & $107 / 115$ & $46 / 171$ & $193 / 209$ & & & & $190 / 218$ \\
\hline & & $39 / 274$ & 74/194 & $38 / 171$ & 39/183 & $68 / 190$ & $13 / 171$ & $113 / 146$ & $9 / 327$ & $28 / 143$ & & & $193 / 209$ & & $80 / 199$ & & \\
\hline & $8 / 235$ & $239 / 274$ & 74/194 & $138 / 171$ & $139 / 183$ & $168 / 190$ & $143 / 171$ & $113 / 146$ & $299 / 327$ & $128 / 143$ & $107 / 115$ & $146 / 171$ & $193 / 209$ & $239 / 279$ & $180 / 199$ & $253 / 298$ & $190 / 218$ \\
\hline & $8 / 235$ & $239 / 274$ & $174 / 194$ & $138 / 171$ & $139 / 183$ & $168 / 190$ & $143 / 171$ & $113 / 146$ & $299 / 327$ & $128 / 143$ & $107 / 115$ & $146 / 171$ & $193 / 209$ & $239 / 279$ & $180 / 199$ & $253 / 298$ & $190 / 218$ \\
\hline & & $39 / 274$ & $174 / 194$ & $138 / 171$ & $139 / 183$ & $168 / 190$ & $43 / 171$ & $113 / 146$ & $99 / 327$ & $128 / 143$ & $107 / 115$ & $146 / 146$ & $193 / 209$ & & $80 / 199$ & & \\
\hline & & $39 / 274$ & 74/194 & $38 / 171$ & $39 / 183$ & $88 / 190$ & $43 / 171$ & $113 / 146$ & & $128 / 143$ & & & $193 / 209$ & & 80/199 & & $/ 218$ \\
\hline & & $239 / 274$ & $174 / 194$ & $138 / 171$ & $139 / 183$ & $168 / 190$ & $143 / 171$ & $113 / 146$ & $299 / 327$ & $128 / 143$ & $107 / 115$ & $146 / 146$ & $193 / 209$ & & $180 / 199$ & & $190 / 218$ \\
\hline & & $39 / 274$ & $174 / 194$ & $138 / 171$ & $139 / 183$ & $168 / 190$ & $43 / 171$ & $113 / 146$ & 27 & 143 & & & $193 / 209$ & & $180 / 199$ & & $/ 190$ \\
\hline & & 274 & $174 / 194$ & $138 / 171$ & $139 / 183$ & $168 / 190$ & $43 / 171$ & $113 / 146$ & 27 & $128 / 143$ & $107 / 115$ & $146 / 171$ & $193 / 209$ & & $180 / 199$ & & \\
\hline & & 274 & $74 / 174$ & $138 / 171$ & $139 / 183$ & $168 / 190$ & 13/171 & $113 / 146$ & & $128 / 143$ & $107 / 107$ & $146 / 171$ & $193 / 209$ & & $180 / 180$ & & $/ 218$ \\
\hline & & $239 / 274$ & $174 / 174$ & $138 / 171$ & $139 / 183$ & $168 / 190$ & $143 / 171$ & $146 / 146$ & $299 / 2$ & $128 / 143$ & $107 / 115$ & $146 / 146$ & $193 / 209$ & & $180 / 180$ & & $190 / 218$ \\
\hline & 15 & $239 / 2$ & $174 / 194$ & $138 / 171$ & $139 / 183$ & $168 / 190$ & $43 / 171$ & $113 / 146$ & 299 & 143 & & & $193 / 209$ & & $180 / 180$ & & \\
\hline & & 74 & $174 / 194$ & $138 / 171$ & $139 / 183$ & $168 / 190$ & $43 / 171$ & $113 / 146$ & 299 & $128 / 143$ & $107 / 115$ & $146 / 171$ & $193 / 209$ & & $180 / 199$ & & 18 \\
\hline & & $39 / 274$ & 74/194 & $138 / 171$ & $139 / 183$ & $168 / 190$ & $43 / 171$ & $113 / 146$ & 27 & $128 / 143$ & $107 / 107$ & $146 / 171$ & $193 / 193$ & & $180 / 199$ & & $/ 218$ \\
\hline & $198 / 235$ & $239 / 274$ & $174 / 194$ & $138 / 171$ & $139 / 183$ & $168 / 190$ & $143 / 171$ & $113 / 146$ & $299 /$. & $128 / 143$ & $107 / 115$ & $146 / 171$ & $193 / 209$ & & $180 / 199$ & & $190 / 218$ \\
\hline & & $239 /$ & $174 / 194$ & $/ 171$ & $139 / 183$ & $168 / 190$ & $43 / 171$ & $113 / 146$ & 27 & 43 & & & /209 & & $180 / 199$ & & \\
\hline & & 74 & 74/194 & $38 / 171$ & $139 / 183$ & $168 / 190$ & $43 / 171$ & $113 / 146$ & 299 ) & $128 / 143$ & $107 / 115$ & $146 / 171$ & $193 / 209$ & & $180 / 199$ & & 190/2 \\
\hline & & $239 / 274$ & $174 / 194$ & $138 / 171$ & $139 / 183$ & $168 / 190$ & $143 / 171$ & $113 / 146$ & 27 & $128 / 143$ & $107 / 115$ & 171 & $193 / 209$ & & $180 / 199$ & & \\
\hline & $198 / 235$ & $239 / 274$ & $174 / 194$ & $138 / 171$ & $139 / 183$ & $168 / 190$ & $143 / 171$ & $113 / 146$ & $299 /$ & $128 / 143$ & $115 / 115$ & & $193 / 209$ & & $180 / 199$ & & 218 \\
\hline & & 74 & $174 / 194$ & $3 / 171$ & $139 / 183$ & $168 / 190$ & $3 / 171$ & $113 / 146$ & & $8 / 143$ & & & $193 / 209$ & & $180 / 199$ & & \\
\hline & & $239 /$ & $174 / 194$ & $38 / 171$ & $139 / 183$ & $168 / 190$ & $43 / 171$ & $113 / 146$ & $299 /$ & $128 / 143$ & $115 / 115$ & $146 / 171$ & $193 / 209$ & & $180 / 199$ & & $190 / 218$ \\
\hline & & $239 / 274$ & $174 / 194$ & $138 / 171$ & $139 / 183$ & $168 / 190$ & $143 / 171$ & $113 / 146$ & 27 & $128 / 143$ & $115 / 115$ & $146 / 171$ & $193 / 209$ & & $180 / 199$ & & \\
\hline & $198 / 2$ & $239 / 274$ & $174 / 194$ & $138 / 171$ & $139 / 183$ & $168 / 190$ & $143 / 171$ & $113 / 146$ & 27 & $128 / 143$ & $115 / 1$ & & $193 / 209$ & & $180 / 199$ & & \\
\hline & & $239 / 2$ & $174 / 194$ & $138 / 171$ & $139 / 183$ & $168 / 190$ & $43 / 171$ & $113 / 146$ & & & & & 209 & & $180 / 199$ & & \\
\hline & & $239 / 2$ & $174 / 194$ & $138 / 171$ & $139 / 183$ & $168 / 190$ & $43 / 171$ & $113 / 146$ & & $/ 143$ & & 171 & $193 / 209$ & & $180 / 199$ & & \\
\hline & & $239 / 274$ & 74/194 & $138 / 171$ & $139 / 183$ & $168 / 190$ & $143 / 171$ & $113 / 146$ & & $128 / 143$ & & & $193 / 209$ & & $180 / 199$ & & \\
\hline & & $239 /$ & $174 / 194$ & & $139 / 1$ & $168 / 190$ & & 146 & & & & & & & /199 & & \\
\hline & & 74 & $174 / 194$ & 171 & $139 / 183$ & $168 / 190$ & $43 / 171$ & $113 / 146$ & & $8 / 143$ & & & $193 / 209$ & & $180 / 199$ & & \\
\hline & & $239 / 274$ & $174 / 194$ & $/ 171$ & $139 / 183$ & $168 / 190$ & $43 / 171$ & $113 / 146$ & 27 & 143 & $107 / 115$ & & $193 / 209$ & & $180 / 199$ & & $190 / 218$ \\
\hline & & $239 / 274$ & $174 / 194$ & & $139 / 183$ & $168 / 190$ & $143 / 171$ & $113 / 146$ & & & & & & & $180 / 199$ & & \\
\hline & & $239 / 274$ & $174 / 194$ & & $139 / 183$ & $168 / 190$ & $43 / 171$ & $113 / 146$ & & & & & & & $180 / 199$ & & \\
\hline & & $9 / 274$ & $174 / 194$ & $/ 171$ & $139 / 183$ & $168 / 190$ & $43 / 171$ & $113 / 113$ & 299 & $28 / 143$ & $107 / 1$ & $146 / 146$ & $193 / 193$ & & $180 / 180$ & & $190 / 218$ \\
\hline & & $239 / 274$ & $174 / 194$ & $138 / 171$ & $139 / 183$ & $168 / 190$ & $143 / 171$ & $113 / 113$ & 27 & $/ 143$ & $107 / 107$ & $146 / 171$ & $193 / 193$ & & $180 / 180$ & & $190 / 218$ \\
\hline & & $239 / 274$ & $174 / 194$ & $138 / 171$ & $139 / 183$ & $168 / 190$ & $143 / 171$ & $113 / 146$ & & & & & $193 / 209$ & & $180 / 180$ & & 218 \\
\hline & & 2. & $174 / 174$ & & & $68 / 190$ & & & & & & & & & & & \\
\hline & 1 & $9 / 274$ & $174 / 174$ & 171 & $139 / 183$ & $168 / 190$ & $3 / 171$ & $146 / 146$ & 299 & $/ 143$ & & 146 & $193 / 193$ & & $180 / 199$ & & $190 / 218$ \\
\hline & & $239 / 274$ & $174 / 194$ & $138 / 171$ & $139 / 183$ & $168 / 190$ & $143 / 171$ & $113 / 146$ & & $/ 143$ & $107 / 115$ & $146 / 171$ & $193 / 209$ & & $180 / 199$ & & $190 / 190$ \\
\hline & & $239 / 274$ & $174 / 194$ & $138 / 171$ & $139 / 183$ & $168 / 190$ & $143 / 171$ & $146 / 146$ & $99 / 327$ & $128 / 143$ & & $146 / 171$ & $193 / 193$ & & $180 / 180$ & & $190 / 190$ \\
\hline & & & $174 / 194$ & & & & & & & & & & & & 199 & & $190 / 218$ \\
\hline & $198 / 235$ & $239 / 274$ & $174 / 194$ & $138 / 171$ & $139 / 183$ & $168 / 190$ & $143 / 171$ & $113 / 146$ & $299 /$ & $128 / 143$ & $107 / 115$ & $146 / 171$ & $193 / 209$ & 239 & $180 / 180$ & & $190 / 190$ \\
\hline & $198 / 235$ & $239 / 274$ & $174 / 194$ & $138 / 171$ & $139 / 183$ & $168 / 190$ & $143 / 171$ & $113 / 146$ & $299 / 327$ & $128 / 143$ & $107 / 115$ & $146 / 146$ & $193 / 193$ & & $180 / 180$ & $/ 298$ & $190 / 190$ \\
\hline & & $39 / 274$ & $174 / 194$ & & & $68 / 190$ & & & & & & & $/ 209$ & & $180 / 199$ & & $/ 218$ \\
\hline & & $239 / 274$ & $174 / 194$ & & & & & & & & & & & & $180 / 180$ & & $190 / 218$ \\
\hline & & $239 / 274$ & $174 / 194$ & $138 / 171$ & $139 / 183$ & $168 / 190$ & $143 / 171$ & $146 / 146$ & & $128 / 143$ & $115 / 115$ & $6 / 171$ & $193 / 209$ & & $180 / 199$ & & $190 / 190$ \\
\hline & $198 / 235$ & $239 / 274$ & $174 / 194$ & $138 / 171$ & $139 / 183$ & $168 / 190$ & $143 / 171$ & $146 / 146$ & $299 / 327$ & $128 / 143$ & $115 / 115$ & $146 / 171$ & $193 / 193$ & $239 / 279$ & $180 / 180$ & $253 / 298$ & $190 / 190$ \\
\hline & & & & & & & & & & & & & & & & & $190 / 190$ \\
\hline & & $239 / 274$ & $174 / 174$ & & & & & & & & & & & & & & $190 / 190$ \\
\hline & $198 / 235$ & $239 / 274$ & $174 / 194$ & $138 / 171$ & $139 / 183$ & $168 / 190$ & $143 / 171$ & $146 / 146$ & 299/299 & $128 / 143$ & $115 / 115$ & $146 / 171$ & $193 / 193$ & $239 / 279$ & $180 / 199$ & $253 / 298$ & $190 / 218$ \\
\hline
\end{tabular}


Table II

(Continuation)

(Continuação)

\begin{tabular}{|c|c|c|c|c|c|c|c|c|c|c|c|c|c|c|c|c|c|}
\hline Loci & $\begin{array}{c}\text { Scu1 } \\
0 v v\end{array}$ & $\begin{array}{l}\text { Scu } \\
11 v v\end{array}$ & $\begin{array}{c}\text { Scu } 15 \\
v v\end{array}$ & $\begin{array}{c}U d v \\
26\end{array}$ & $\begin{array}{c}U d v \\
32\end{array}$ & $\begin{array}{c}U d v \\
34\end{array}$ & $\begin{array}{c}U d v \\
40\end{array}$ & $\begin{array}{c}U d v \\
44\end{array}$ & $\begin{array}{c}U d v \\
74\end{array}$ & $\begin{array}{c}U d v \\
85\end{array}$ & $\begin{array}{c}U d v \\
96\end{array}$ & $\begin{array}{l}U d v \\
107\end{array}$ & $\begin{array}{l}U d v \\
108\end{array}$ & $\begin{array}{c}V v m \\
d 5\end{array}$ & $\begin{array}{c}\text { Vvm } \\
\text { d6 }\end{array}$ & $\begin{array}{c}V v m \\
d 7 \\
\end{array}$ & Vvs3 \\
\hline M53 & $198 / 235$ & $239 / 274$ & $174 / 194$ & $138 / 171$ & $139 / 183$ & $168 / 190$ & $143 / 171$ & $113 / 146$ & 299/327 & $128 / 143$ & $115 / 115$ & $146 / 171$ & $193 / 209$ & $239 / 279$ & $180 / 199$ & $253 / 298$ & $190 / 218$ \\
\hline M54 & $198 / 235$ & $239 / 274$ & $174 / 194$ & $138 / 171$ & $139 / 183$ & $168 / 190$ & $143 / 171$ & $113 / 146$ & 299/327 & $128 / 143$ & $115 / 115$ & $146 / 171$ & $193 / 209$ & $239 / 279$ & $180 / 199$ & $253 / 298$ & $190 / 218$ \\
\hline M55 & $198 / 235$ & $239 / 274$ & $174 / 194$ & $138 / 171$ & $139 / 183$ & $168 / 190$ & $143 / 171$ & $113 / 146$ & $299 / 327$ & $128 / 143$ & $115 / 115$ & $146 / 171$ & $193 / 209$ & $239 / 279$ & $180 / 180$ & $253 / 298$ & $190 / 218$ \\
\hline M56 & $198 / 235$ & $239 / 274$ & $174 / 194$ & $138 / 171$ & $139 / 183$ & $168 / 190$ & $143 / 171$ & $113 / 146$ & $299 / 327$ & $128 / 143$ & $107 / 115$ & $146 / 171$ & $193 / 209$ & $239 / 279$ & $180 / 199$ & $253 / 298$ & $190 / 218$ \\
\hline M57 & $198 / 235$ & $239 / 274$ & $174 / 194$ & $138 / 171$ & $139 / 183$ & $168 / 190$ & $143 / 171$ & $113 / 146$ & 299/299 & $128 / 143$ & $107 / 115$ & $146 / 171$ & $193 / 209$ & $239 / 279$ & $180 / 199$ & $253 / 298$ & $190 / 218$ \\
\hline M58 & $198 / 235$ & $239 / 274$ & $174 / 194$ & $138 / 171$ & $139 / 183$ & $168 / 190$ & $143 / 171$ & $113 / 146$ & $299 / 299$ & $128 / 143$ & $107 / 107$ & $146 / 171$ & $193 / 209$ & $239 / 279$ & $180 / 180$ & $253 / 298$ & $190 / 218$ \\
\hline M59 & $198 / 235$ & $239 / 274$ & $174 / 194$ & $138 / 171$ & $139 / 183$ & $168 / 190$ & $143 / 171$ & $113 / 146$ & 299/299 & $128 / 143$ & $107 / 115$ & $146 / 171$ & $193 / 209$ & $239 / 279$ & $180 / 180$ & $253 / 298$ & $190 / 218$ \\
\hline P60 & $198 / 235$ & $239 / 274$ & $174 / 174$ & $138 / 171$ & $139 / 183$ & $168 / 190$ & $143 / 171$ & $113 / 113$ & $299 / 327$ & $128 / 143$ & $107 / 115$ & $146 / 171$ & $193 / 209$ & $239 / 279$ & $180 / 180$ & $253 / 298$ & $190 / 448$ \\
\hline P61 & $198 / 235$ & $239 / 274$ & $174 / 194$ & $138 / 171$ & $139 / 183$ & $168 / 190$ & $143 / 171$ & $113 / 113$ & 299/327 & $128 / 143$ & $115 / 115$ & $146 / 146$ & $193 / 193$ & $239 / 279$ & $180 / 180$ & $253 / 298$ & $448 / 448$ \\
\hline P62 & $198 / 235$ & $239 / 274$ & $174 / 174$ & $138 / 171$ & $139 / 183$ & $168 / 190$ & $143 / 171$ & $113 / 113$ & 299/327 & $128 / 143$ & $140 / 140$ & $146 / 146$ & $193 / 209$ & $239 / 239$ & $180 / 180$ & $253 / 298$ & $448 / 448$ \\
\hline P63 & $198 / 235$ & $239 / 274$ & $174 / 194$ & $138 / 171$ & $139 / 183$ & $168 / 190$ & $143 / 171$ & $113 / 113$ & $299 / 327$ & $128 / 143$ & $115 / 115$ & $146 / 171$ & $193 / 209$ & $239 / 279$ & $180 / 180$ & $253 / 298$ & $190 / 448$ \\
\hline P64 & $198 / 235$ & $239 / 274$ & $174 / 194$ & $138 / 171$ & $139 / 183$ & $168 / 190$ & $143 / 171$ & $113 / 113$ & $299 / 327$ & $128 / 143$ & $115 / 115$ & $146 / 171$ & 209/209 & $239 / 279$ & $180 / 180$ & $253 / 298$ & $448 / 448$ \\
\hline P65 & $198 / 235$ & $239 / 274$ & $174 / 194$ & $138 / 171$ & $139 / 183$ & $168 / 190$ & $143 / 171$ & $113 / 113$ & 299/327 & $128 / 143$ & $115 / 115$ & $146 / 171$ & $193 / 209$ & $239 / 279$ & $180 / 180$ & $253 / 298$ & $448 / 448$ \\
\hline P66 & $198 / 235$ & $239 / 274$ & $174 / 194$ & $138 / 171$ & $139 / 183$ & $168 / 190$ & $143 / 171$ & $113 / 113$ & 299/327 & $128 / 143$ & $115 / 115$ & $146 / 171$ & $193 / 209$ & $239 / 279$ & $180 / 180$ & $253 / 298$ & $190 / 448$ \\
\hline P67 & $198 / 235$ & $239 / 274$ & $174 / 174$ & $138 / 171$ & $139 / 183$ & $168 / 190$ & $143 / 171$ & $113 / 113$ & $299 / 327$ & $128 / 143$ & $115 / 115$ & $146 / 171$ & $209 / 209$ & $239 / 239$ & $180 / 180$ & $253 / 298$ & $448 / 448$ \\
\hline P68 & $198 / 235$ & $239 / 274$ & $174 / 174$ & $138 / 171$ & $139 / 183$ & $168 / 190$ & $143 / 171$ & $113 / 113$ & $299 / 327$ & $128 / 143$ & $115 / 115$ & $146 / 171$ & 209/209 & $239 / 279$ & $180 / 180$ & $253 / 298$ & $448 / 448$ \\
\hline P69 & $198 / 235$ & $239 / 274$ & $174 / 194$ & $138 / 171$ & $139 / 183$ & $168 / 190$ & $143 / 171$ & $113 / 113$ & $299 / 327$ & $128 / 143$ & $115 / 115$ & $146 / 171$ & $193 / 209$ & $239 / 279$ & $180 / 180$ & $253 / 298$ & $190 / 448$ \\
\hline
\end{tabular}

1-15 J - \$les

- $16=30$ - 15 W Wigal Artunjo

60-69 P-pripandu

\section{Table III}

Number of alleles $(\mathrm{Na})$ and number of effective alleles $(\mathrm{Ne})$ per polymorphic locus, mean observed heterozygosity $\left(\mathrm{H}_{\mathrm{o}}\right)$ and expected heterozygosity $\left(\mathrm{H}_{\mathrm{e}}\right)$ in microsatellite loci of cv. 'Italy' of

Vitis vinifera from six vineyards in two Brazilian states: Paraná (PR) and São Paulo (SP)

Número de alelos ( $\mathrm{Na}$ ) e número efetivo de alelos ( $\mathrm{Ne}$ ) por loco polimórfico, heterozigosidade média observada (Ho) e heterozigosidade média esperada (He) nos locos microssatélites da cultivar 'Italy' de Vitis vinifera dos seis parreirais em dois estados Brasileiros: Paraná (PR) e São Paulo (SP)

\begin{tabular}{lcccc}
\hline \multicolumn{1}{c}{ Sample } & Na & Ne & Ho & He \\
\hline Marialva, PR & 2.0 & 1.9546 & 0.9160 & 0.4868 \\
Paiçandu, PR & 1.94 & 1.7838 & 0.7000 & 0.4085 \\
Uraí, PR & 2.0 & 1.7548 & 0.7020 & 0.4064 \\
Pilar do Sul, SP & 2.0 & 1.9261 & 0.8908 & 0.4778 \\
São Miguel Arcanjo, SP & 2.0 & 1.9822 & 0.9647 & 0.4949 \\
Jales, SP & 2.0 & 1.9815 & 0.9451 & 0.4950 \\
\hline Mean & 2.11 & 1.9763 & 0.8525 & 0.4923 \\
\hline
\end{tabular}

Different allele frequencies in nine microsatellites of cv. 'Italy' estimated a moderate genetic divergence $\left(0.05<\mathrm{F}_{\mathrm{ST}}<0.15\right)$ between the vines of Marialva, Paiçandu, Uraí, Jales, Pilar do Sul and São Miguel Arcanjo. Genetic divergence among the six vineyards resulted in $\mathrm{F}_{\mathrm{ST}}=0.0648$.

In spite of the somatic mutations leading to new alleles $\left(U d v 96^{140}\right.$ and $\left.V v s 3^{448}\right)$ and in spite of changes in the allele frequencies in $53 \%$ of microsatellite loci, the similarity coefficient (Nei, 1978) between the vineyards ranged between 0.8520 (between Urai and Paiçandu) and 1.000 (between Jales and Pilar do Sul, Jales and São Miguel Arcanjo, Jales and Marialva, Pilar do Sul and Marialva, and São Miguel Arcanjo and Marialva) (Table IV). High genetic identity indicates a common origin for the vineyards of cv. 'Italy' introduced in the state of São Paulo and its culture in the north of the state of Paraná (Camargo, 1994). Genetic identity rates are important for winegrowers to foreground cultural practices in vineyards. In the case of vineyards with $100 \%$ identity rates, such as the samples analyzed in current study, it may be possible, for instance, to adopt similar options and procedures for the control of pathogens infection.

The dendrogram generated by Nei's coefficient from the analysis of individual vines of cv. 'Italy' (constructed from 17 microsatellite primers data using adegenet package from R Development Core Team, 2013) identified two well-defined larger groups and two smaller groups formed by vines from six cv. 'Italy' vineyards (Figure 2). Dendrogram showed several homogeneous groups formed by vines from São Miguel Arcanjo (80\%), Jales (60\%), Urai (53\%), and Paiçandu $(80 \%)$ vineyards. Heterogeneous groups were also formed by mixture of vines from different vineyards. Genetic identity in the dendrogram was evident between $60 \%$ of the vines of the same or of different vineyards. Vines from Jales, Pilar do Sul, Urai, Marialva, and São Miguel Arcanjo vineyards 
showed genetic identity, so that the six 'Italy' vineyards represented a moderate genetic divergence.

\section{Table IV}

Nei's genetic identity (1978) between vineyards of 'Italy' (Vitis vinifera L.) cultivated in different regions of Southern (Marialva, Paiçandu, Urai) and Southwest Brazil (Pilar do Sul, São Miguel Arcanjo, Jales) as reveled by 17 microsatellite loci

Identidade genética de Nei (Nei, 1978) entre os parreirais de uvas 'Italy' (Vitis vinifera L.) cultivadas nas regiões Sul (Marialva, Paiçandu, Urai) e Sudeste (Pilar do Sul, São Miguel Arcanjo, Jales) do Brasil, revelada pelos 17 locos microssatélites

\begin{tabular}{lcccccc}
\hline & $\begin{array}{c}\text { Marial- } \\
\text { va }\end{array}$ & $\begin{array}{c}\text { Paiçan- } \\
\text { du }\end{array}$ & Urai & $\begin{array}{c}\text { Pilar do } \\
\text { Sul }\end{array}$ & $\begin{array}{c}\text { São Miguel } \\
\text { Arcanjo }\end{array}$ & Jales \\
\hline Marialva & --- & 0.9189 & 0.9625 & 1.0000 & 1.0000 & 1.0000 \\
Paiçandu & & --- & 0.8520 & 0.8902 & 0.9026 & 0.8904 \\
$\quad$ Urai & & & --- & 0.9345 & 0.9451 & 0.9474 \\
Pilar do Sul & & & & --- & 0.9932 & 1.0000 \\
São Miguel & & & & & & \\
Arcanjo & & & & & --- & 1.0000 \\
$\quad$ Jales & & & & & & -- \\
\hline
\end{tabular}

Occurrence of new alelles with definite frequencies was detected only at $U d v 96$ and $V v s 3$ loci in the cv.
'Italy' from Paiçandu (Table II). However, an extra allele observed as having an intensity comparable with the two original alleles was evident in two plants of cv. 'Italy' from Urai and four plants from São Miguel do Iguaçu using the UDV107 primer. The primer SCU10VVW also detected a third allele in three plants of cv. 'Italy' from São Miguel Arcanjo, six plants from Marialva, and two plants from Paiçandu. The extra alleles observed as having an intensity comparable with the two original alleles defined a triallelic pattern at $U d v 107$ and $S c u 10 v v w$ microsatellite loci. The tri-allelic phenotype was not considered at analysis of polymorphism in the SSR loci of cv. 'Italy', but is important to highlight a third allele extra at SSR locus since the detection of three alleles at the same locus could be the result of a chimeric structure in which genotypes of different layers of cells displayed different alleles. The tri-allelic pattern in SSR loci have been considered an evidence of chimeras, a mechanism of genetic diversification well characterized by Hocquigny et al. (2004) occurring in grapevines clones (Crespan, 2004; Moncada et al., 2006). In cv. 'Italy' vines the chimeras were evident in $13 \%, 46 \%, 85 \%$, and $20 \%$ of the plants from Urai, São Miguel Arcanjo, Marialva, and Paiçandu, respectively.

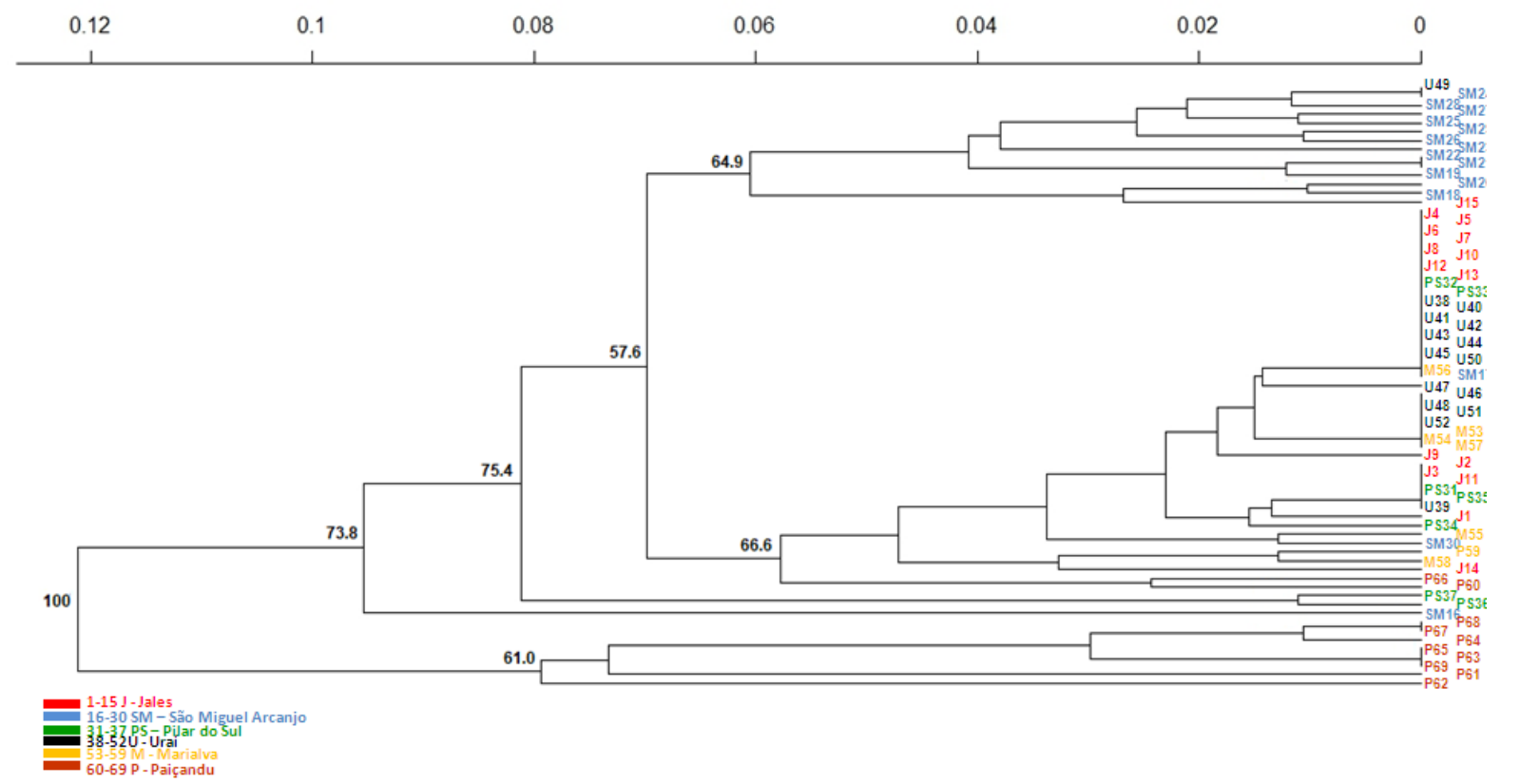

Figure 2. Dendrogram generated by Jaccard coefficient from analysis of individual vines of the six cv. 'Italy' vineyards from: Urai (U), São Miguel Arcanjo (SM), Jales (J), Pilar do Sul (PS), Marialva (M), and Paiçandu (P) in Paraná (U, M, P) and São Paulo (SM, J, PS) States of Brazil based on 17 microsatellite markers. Numbers beside nodes indicate relative bootstrap frequencies (\%).

Dendrograma gerado pelo coeficiente de Jaccard a partir da análise de plantas individuais dos seis parreirais da cultivar 'Italy': Urai (U), São Miguel Arcanjo (SM), Jales (J), Pilar do Sul (PS), Marialva (M), e Paiçandu (P) nos estados do Paraná (U, M, P) e São Paulo (SM, J, PS), Brasil, baseado nos 17 marcadores microssatélites. Os números junto aos nós indicam a frequência relativa (\%) do bootstrap. 
High level of mean observed heterozygosity in microsatellite loci is expected for cv. 'Italy' as a product of the cross between the 'Bicane' and 'Moscat Hamburg' cultivars (Sousa, 1996). Most grape cultivars are highly heterozygous (Di VecchiStaraz et al., 2009; This et al., 2011) due to vegetative (clonal) propagation to maintain the selected genotypes. High Ho rates have been reported in cultivars of Central Europe (Ho $=0.776-0.904$; Sefc et al., 2000) and Spain (Ho = $0.756-0.909$; Martín et al., 2003, and Ho $=0.744-0.949$; FernándezGonzález et al., 2007), in cultivars of Tunisia (Ho = $0.71-0.98$; Snoussi et al., 2004) and also in different species of Vitis $(\mathrm{Ho}=0.68-0.92$; Fernández et al., 2008). High rates of observed heterozygosity $(\mathrm{Ho}=$ $0.743-0.857$; Carimi et al., 2010, and Ho $=0.78-$ 0.92; Alba et al., 2014, respectively) were reported in genotypes of Italian grapevines and Italian table grapes (cultivars and candidate cultivars). Lower rates with greater interval were reported in cultivars in Portugal (Ho $=0.60-0.97$ and $0.55-0.91$; Lopes et al., 1999, 2006), in North America (Ho = $0.30-1.0$; Pollefeys and Bousquet, 2003), in hybrids of France $(\mathrm{Ho}=0.0$ - 1.0; Merdinoglu et al., 2005), in Peruvian and Argentine Criollas varieties $(\mathrm{Ho}=0.615-1.000$; Martínez et al., 2006), and in Iranian grape cultivars $(\mathrm{Ho}=0.49-0.97$; Doulati-Baneha et al., 2013). High rates of observed heterozygosity in the cv. 'Italy' (Ho $=0.7000-0.9647$; Table III) agrees to the highest Ho values reported for cultivars of Central Europe, Spain, Tunisia, and different Italian genotypes and species of Vitis.

Somatic mutations are also expected in the vegetative propagation of cv. 'Italy'. Alleles $U d v 96^{140}$ and $V v s 3^{448}$ detected only in the vines of Paiçandu (Table II) evidence somatic mutations at molecular level in cv. 'Italy'. Somatic mutations in microsatellite loci of clones are more often detected by screening large numbers of loci and clones. Riaz et al. (2002) detected intra-varietal polymorphism in 17 microsatellite markers when 100 markers were genotyped in more than 20 clones each for 'Pinot noir' and 'Chardonnay'. Higher polymorphism was detected in 49 microsatellites of 145 clones of 'Pinot' cultivar (22.4\%; Hocquigny et al., 2004) and in 84 microsatellite loci of 59 clones of 'Cabernet Sauvignon' (21.4\%; Moncada et al., 2006). Current authors detected somatic mutations in two microsatellite loci in cv. 'Italy' after screening of only 17 loci in six clones: a polymorphism of $11.8 \%$, which was consistent with rate described by Moncada and Hinrichsen (2007) in the analysis of 20 loci in 25 clones of 'Carmenére' (10\%) from Chile, France and Italy.
On the other hand, the polymorphism at microsatellite loci of the cv. 'Italy' may be higher than $11.8 \%$ if the chimeras pattern is considered since the tri-allelic pattern at microsatellite loci have been proposed as a mechanism of genetic diversification in grapevines clones (Crespan, 2004; Hocquigny et al., 2004; Moncada et al., 2006), which have vegetative propagation. The tri-allelic pattern at $U d v 107$ and Scu10vv loci has been observed in $24 \%$ of vines in cv. 'Italy' from Uraí (13\%), São Miguel Arcanjo (46\%), Marialva (85\%), and Paiçandu (20\%). The presence of a third allele in SSR locus is an indicative of these loci potential in molecular diversification and variability. Thus, in addition to the somatic mutation in $U d v 96$ and $V v s 3$ loci the detection of extra alleles may be conferring high genetic diversity also for the Udv107 and SculOvv loci in cv. 'Italy' vines cultivated in the six regions of southern and southeastern Brazil. The cause and effects of somatic mutations at microsatellite loci of cv. 'Italy' are unknown and there are doubts if mutations are related to the age of the vineyards. Somatic mutation in $U d v 96$ and $V v s 3$ loci does not seem to be more frequent in the oldest vineyards. It was not possible to know the age of the vineyards established in Urai, Jales, Pilar do Sul and São Miguel Arcanjo. However, in Paiçandu where somatic mutations occurred at $U d v 96$ and $V v s 3$ loci, the cv. 'Italy' vineyards were established in 1997, or rather, 35 years after the start of vineyard cultivation in Marialva in 1962 (M. Collet, personal information). The oldest vineyards of cv. 'Italy' in Marialva showed greater genetic stability than the most recently vineyards established in Paiçandu. In contrast, the chimeras were more evident in vines from Marialva $(85 \%)$. It may be supposed that the older varieties were exposed for a longer time to environmental stress and therefore they had a great chance to accumulate more mutations (Pelsy, 2010).

The genetic potential of Paiçandu vineyards should be underscored. Somatic variants potentially represent a commercial interest if they improve an important agronomical trait (e.g., height, yield, pathogen susceptibility and others) or provide innovation of the product (This et al., 2011). The vineyards of Paiçandu with low genetic stability (greater genetic variability) should be more carefully investigated as a source of somatic mutants with favorable agronomic traits. Somatic mutations contribute towards the generation of genetic variation which may be relevant for improvements. They may eventually give rise to plant variants without going through the gametophytic phase. Somatic variation has a strong relevance in the generation of the cultivars 'Rubi', 'Benitaka', 
'Brasil', 'Redmeire' and 'Black Star' (Kishino and Mashima, 1980; Sousa, 1996; Pires et al., 2003; Roberto et al., 2012) from cv. 'Italy' as the fundamental genome.

Genetic diversity as a result of changes in allele frequencies in $53 \%$ of the microsatellite loci (Scu15vv, Udv44, Udv74, Udv96, Udv107, Udv108, $V v m d 5, V v m d 6$, and $V v s 3$ loci) was more frequently detected than somatic mutations due to new alleles. Changes in allele frequencies occurred at different loci in different cv. 'Italy' vineyards of the six regions (Table II). Several factors may be related with evidences of changes in allele frequencies in microsatellite locus, including the random selection of genotypes (homozygous or heterozygous for microsatellite loci here analyzed) for the establishment of a new vineyard by vegetative propagation. Different values of Ho for the same variety multiplied by vegetative propagation on the two or more cultivated areas may be due to different genotypes of cv. 'Italy' used in the foundation of the cultivated areas. Other plausible hypothesis to explain different values of Ho for the same variety multiplied by vegetative propagation may be that plants identified as homozygous in the microsatellite loci in vineyards of the six regions may contain null alleles masking the identification of the original phenotype reported as heterozygote. Somatic mutations may lead to the appearance of null alleles and mutations in sequences of microsatellite flanking regions of grapes were confirmed by sequencing (Fernández et al., 2008) and associated to the emergence of null alleles. High frequency of null EST-3 carboxylesterase phenotype (52.3\%) has been suggested in cvs. 'Italy' (Orasmo et al., 2007). Null alleles in microsatellite loci have also been reported in varieties and cultivars of grapes from Portugal (Lopes et al., 1999), Spain (Martín et al., 2003) and in North American hybrids and in cultivars from France (Pollefeys and Bousquet, 2003).

The occurrence of somatic crossing-over events is another factor that may lead to changes in the frequency of alleles in microsatellite locus with the emergence of homozygous phenotypes. The somatic recombination induced by retrotransposons was used to explain changes in frequency for berry skin color in the colored ('Benitaka' and 'Brasil') cv. 'Italy' (Oliveira-Collet et al., 2005) and in the high frequency of the null EST-3 carboxylesterase phenotype within cv. 'Italy' (Orasmo et al., 2007). For the 'Benitaka' cultivar, Azuma et al. (2009) showed that color recovery was due to a new allelic form of $V v m y b A l$ gene formed by illegitimate homologous recombination between $V v m y b A l$ and $V v m y b A 3$ genes that originated the $V v m y b A 1^{B E N}$ allele. Somatic crossing-over events in microsatellite loci may have caused the apparently different random frequencies of alleles in the nine microsatellite loci (Scu15vv, Udv44, Udv74, Udv96, Udv107, Udv108, $V v m d 5, V v m d 6$, and Vvs3 loci) of cv. 'Italy' from Marialva, Paiçandu, Uraí, Jales, Pilar do Sul and São Miguel Arcanjo (Table II).

Double-strand breaks in DNA leading to the occurrence of somatic recombination may be caused by external factors in response of pathogen attack and/or poisons used to their control, or by internal factors during replication and transposon excision and even in response to intrinsic metabolic activities induced by external factors (Schuermann et al., 2005). Geminivirus infection in experimental conditions also promoted somatic homologous recombination (Richter et al., 2014). Consequently, the exposition of leaves of cv. 'Italy' in different types and concentrations of fungicides and poisons (frequently applied for disease control; M. Collet, personal information) may induce point mutations and/or chromosomal breaks that contribute towards the enhancement of different frequencies of alleles in microsatellite loci of cvs 'Italy' in different regions. The reaction of fungicides in inhibiting seven carboxylesterases from different loci in the leaves of cv. 'Italy' was described by Orasmo et al. (2015).

The emergence of the new alleles $U d v 96^{140}$ and $V v s 3^{448}$ beside of changes in allele frequencies detected at the loci $S c u 15 v v, U d v 44, U d v 74, U d v 96$, $U d v 107, U d v 108, V v m d 5$, Vvmd6, and $V v s 3$ have leading to a moderate genetic divergence among the six vineyards of cv. 'Italy' maintained by vegetative propagation. Low rates between cultivated grapevine populations have been commonly related with $\mathrm{F}_{\mathrm{ST}}$ pairwise rates ranging between 0.0224 (EasternWestern Europe) and 0.0374 (Western Europe-North Africa). Results showed higher $F_{\text {ST }}$ pairwise rates only when the wild population was compared to other populations of cultivated grapevines. The highest genetic differentiation rate $(0.0747)$ was recorded between wild accessions and North African cultivars (Riahi et al., 2012). A moderate genetic divergence among the vineyards of Italy coupled to the somatic variation may be a very powerful tool to improve the classical cv. 'Italy' and a good insight for producers of new and different varieties. The preservation of the inter- and intra-vineyards diversity must be a goal for producers interested in the selection and use of somatic variation.

Although several studies have demonstrated the ineffectiveness of some microsatellites when genetic diversity within clone collections is addressed (Aradhya et al., 2003; Martínez et al., 2006; Pelsy et 
al., 2010; Emanuelli et al., 2013), current study proved the effectiveness of microsatellites for clonal polymorphism in vegetative propagation of the $\mathrm{cv}$. Italy, due to the somatic variation leading to new alleles and changes in allele frequencies. Polymorphism in microsatellite loci revealed different genetic stability in vineyards of cv. 'Italy' cultivated in six different regions of Brazil. It actually indicates vineyards with low genetic stability as a possible source of somatic mutants revealing traits of agronomic interest capable of generating new cultivars. Furthermore, the microsatellite primers selected in the present study could be used to investigate the genetic stability of somatic mutants derived from the cultivar 'Italy': 'Rubi', 'Benitaka', 'Brasil', 'Black Star' and 'Redmeire'.

\section{CONCLUSIONS}

The microsatellite markers were effective to evidence somatic mutations and alterations in allele frequencies in the SSR loci that led to a moderate genetic divergence among the vineyards of the cultivar 'Italy'

\section{REFERENCES}

Alba V., Bergamini C., Cardone M.F., Gasparro M., Perniola R., Genghi R., Antonacci D., 2014. Morphological variability in leaves and molecular characterization of novel table grape candidate cultivars (Vitis vinifera L.). Mol. Biotechnol., 56, 557-570.

Aradhya M., Wang Y., Walker M.A., Prins B.H., Koehmstedt A.M., Velasco D., Gerrath J.M., Dangl G.S., Preece J.E., 2003. Genetic diversity, structure, and patterns of differentiation in the genus Vitis. Plant Syst. Evol., 299, 317-330.

Azuma A., Kobayashi S., Goto-Yamamoto N., Shiraishi M., Mitani N., Yakushiji H., Koshita Y., 2009. Color recovery in berries of grape (Vitis vinifera L.) 'Benitaka', a bud sport of 'Italia', is caused by a novel allele at the VvmybAl locus. Plant Sci., 176, 470-478.

Bowers J.E., Boursiquot J.M., This P., Chu K., Johansson H., Meredith C.P., 1999. Historical genetics: the parentage of Chardonnay, Gamay, and other wine grapes of northeastern France. Science, 285, 1562-1565.

Bowers J.E., Dangl G.S., Vignani R., Meredith C.P., 1996. Isolation and characterization of new polymorphic simple sequence repeat loci in grape (Vitis vinifera L.). Genome, 39, 628-633.

Camargo U.A., 1994. Uvas do Brasil. Empresa Brasileira de Pesquisa Agropecuária, Centro Nacional de Pesquisa de Uva e Vinho, Brasília, 90 p.

Camargo U.A., 1998. Cultivares para a viticultura tropical no Brasil. Informe Agropecuário - EPAMIG, 19, 15-19.

Carimi F., Mercati F., Abbate L., Sunseri F., 2010. Microsatellite analyses for evaluation of genetic diversity among Sicilian grapevine cultivars. Genet. Resour. Crop Evol., 57, 703-719.

Crespan M., 2004. Evidence on the evolution of polymorphism of microsatellite markers in varieties of Vitis vinifera L. Theor. Appl. Genet., 108, 231-237. maintained by vegetative propagation in the south and southeast regions of Brasil. Polymorphism in microsatellite loci was also useful to identify the genetically more stable vineyards (from Jales and Pilar do Sul) and to estimate the genetic identity among the vineyards of the cv. 'Italy' cultivated in the six localities of the south and southeast regions of Brasil. A prospect for evolution due to somatic mutations in 'Italy' cultivar was more evident in the vineyard of Paiçandu due to the appearance of two new alleles with defined frequencies. Also, evidence of chimeras in the vineyards of Urai, São Miguel Arcanjo, Marialva, and Paiçandu may be highlighted as potential mechanisms of genetic diversification acting as a probable evolutionary force in $66.6 \%$ of the investigated vines.

\section{ACKNOWLEDGMENTS}

The authors would like to thank the Coordenação de Aperfeiçoamento de Pessoal de Nível Superior (CAPES) for its financial support.

Di Gaspero G., Cipriani G., Marrazzo M.T., Andreetta D., Castro M.J.P., Peterlunger E., Testolin R., 2005. Isolation of (AC)nmicrosatellites in Vitis vinifera L. and analysis of genetic background in grapevines under marker assisted selection. Mol. Breed., 15, 11-20.

Di Vecchi-Staraz M., Lucou V., Bruno G., 2009. Low level of pollen-mediated gene flow from cultivated to wild grapevine: consequences for the evolution of the endangered subspecies Vitis vinifera L. ssp silvestris. J. Heredity, 100, 66-75.

Don R.H., Cox P.T., Wainwright B.J., Baker K., Mattick J.S., 1991. "Touchdown" PCR to circumvent spurious priming during gene amplification. Nucl. Acid Res., 19, 4008.

Doulati-Baneha H., Mohammadib S.A., Labra M., 2013. Genetic structure and diversity analysis in Vitis vinifera L. cultivars from Iran using SSR markers. Sci. Hortic., 160, 29-36.

Emanuelli F., Lorenzi S., Grzeskowiak L., Catalano V., Stefanini M., Troggio M., Myles S., Martinez-Zapater J.M., Zyprian E., Moreira F.M., Grando M.S., 2013. Genetic diversity and population structure assessed by SSR and SNP markers in a large germplasm collection of grape. BMC Plant Biol., 13, 39.

Fernández M.P., Nuñez Y., Pons F., Hernáiz S., Gallego F.J., Ibáñez J., 2008. Characterization of sequence polymorphisms from microsatellite flanking regions in Vitis spp. Mol. Breed., 22, 455465 .

Fernández-González M., Mena A., Izquierdo P.J., Martínez J., 2007. Genetic characterization of grapevine (Vitis vinifera L.) cultivars from Castilla La Mancha (Spain) using microsatellite markers. Vitis, 46, 126-130.

Hocquigny S., Pelsy F., Dumas V., Kindt S., Héloir M.C., Merdinoglu D., 2004. Diversification within grapevine cultivars goes through chimeric states. Genome, 47, 579-589. 
Jombart T., 2008. Adeget: a R package for multivariate analysis of genetic markers. Bioinformatics, 24, 1403-1405.

Kishino A.Y., Mashima M., 1980. Uva Vitis vinifera L. In: Fundação Instituto Agronômico do Paraná. Manual Agropecuário para o Paraná, 139-177. Londrina, PR, Brazil

Lopes M.S., Rodrigues dos Santos M., Eiras Dias J.E., Mendonça D., da Câmara Machado A., 2006. Discrimination of Portuguese grapevines based on microsatellite markers. J. Biotechn., 127, 3444.

Lopes M.S., Sefc K.M., Eiras Dias J.E., Steinkellner H., Câmara Machado A., 1999. The use of microsatellites for germplasm management in a Portuguese grapevine collection. Theor. Appl. Genet., 99, 733-739.

Maia S.H.Z., Mangolin C.A., Oliveira-Collet S.A., Machado M.F.P.S., 2009. Genetic diversity in somatic mutants of grape (Vitis vinifera L.) cultivar Italia based on random amplified polymorphic DNA. Genet. Mol. Res., 8, 28-38.

Martín J.P., Borrego J., Cabello F., Ortiz J.M., 2003. Characterization of Spanish grapevine cultivar diversity using sequence-tagged microsatellite site markers. Genome, 46, 10-18.

Martínez L.E., Cavagnaro P.F., Masuelli R.W., Zúñiga M., 2006. SSR-based assessment of genetic diversity in South American Vitis vinifera varieties. Plant Sci., 170, 1036-1044.

Merdinoglu D., Butterlin G., Bevilacqua L., Chiquet V., Adam Blondon A-F., Decroocq S., 2005. Development and characterization of a large set of microsatellite markers in grapevine (Vitis vinifera L) suitable for multiplex PCR. Mol. Breed. 15, 349-366.

Moncada X., Hinrichsen P., 2007. Limited genetic diversity among clones of red wine cultivar 'Carmenere' as revealed by microsatellite and AFLP markers. Vitis, 46, 174-180.

Moncada X., Pelsy F., Merdinoglu D., Hinrichsen P., 2006. Genetic diversity and geographical dispersal in grapevine clones revealed by microsatellite markers. Genome, 49, 1459-1472.

Nei M., 1972. Genetic distance between populations. The American Naturalist, 106, 283-292.

Nei M., 1978. Estimation of average heterozygosity and genetic distance from a small number of individuals. Genetics, 89, 583590.

Oliveira-Collet S.A., Collet M.A., Machado M.F.P.S., 2005. Differential gene expression for isozymes in somatic mutants of Vitis vinifera L. (Vitaceae). Biochem. Syst. Ecol., 33, 691-703.

Orasmo G.R., Oliveira-Collet S.A., Lapenta A.S., Machado M.F.P.S., 2007. Biochemical and genetic polymorphism for carboxylesterase and acetylesterase in grape clones of Vitis vinifera L. (Vitaceae) cultivars. Biochem. Genet., 45, 663-670.

Orasmo G.R., Oliveira-Collet S.A., Mangolin C.A., Lapenta A.S., Machado M.F.P.S., 2015. Esterase isozymes patterns of grape vine (Vitis vinifera L.) are altered in response to fungicide exposure. Acta Scient. Biol. Sci., 37, 463-469.

Pelsy F., 2010. Molecular and cellular mechanisms of diversity within grapevine varieties. Heredity, 104, 331-340.

Pelsy F., Hocquigny S., Moncada X., Barbeau G., Forget D., Hinrichsen P., Merdinoglu D., 2010. An extensive study of the genetic diversity within seven French wine grape variety collections. Theor. Appl. Genet., 120, 1219-1231.

Pires E.J.P., Sawazaki H.E., Terra M.M., Botelho R.V., Conagim A., Nogueira N.A.M., 2003. Redimeire: A natural mutation of cv. Italia in Brazil. Vitis, 42, 55-56.
Pollefeys P., Bousquet J., 2003. Molecular genetic diversity of the French-American grapevine hybrids cultivated in North America. Genome, 46, 1037-1048.

R Development Core Team, 2013. R: A language and environment for statistics computing. R Foundation for Statistical Computing. Vienna, Austria. ISBN 3-900051-07-0, URL http://www.Rproject.org/.

Riahi L., Laucou V., Le Cunff L., Zoghlami N., Boursiquot J.M., Lacombe T., El-Heit K., Mliki A., This P., 2012. Highly polymorphic nSSR markers: A useful tool to assess origin of North African cultivars and to provide additional proofs of secondary grapevine domestication events. Sci. Hortic., 141, 53-60.

Riaz S., Garisson K.E., Dangl G.S., Boursiquot J.M., Meredith C.P., 2002. Genetic divergence and chimerism within ancient asexually propagated wine grape cultivars. J. Am. Soc. Hortic. Sci., 127, 508-514.

Richter K.S., Kleinow T., Jeske H., 2014. Somatic homologous recombination in plants is promoted by a geminivirus in a tissueselective manner. Virology, 452-453, 287-296.

Roberto S.R., Assis A.M., Genta W., Yamamoto L.Y., Sato A.J., 2012. 'Black star': Uma mutação somática natural da uva fina de mesa cv. Brasil. Rev. Brasil. Fruticult., 34, 947-950.

Roberto S.R., Mashima C.H., Colombo, R.C., 2015. Phenological characterization and quality of fine 'Black Star' table grape. Agron. Sci. Biotechn., 1, 77-82.

Roberto S.R., Mashima C.H., Colombo R.C., Assis A.M., Koyama R., Yamamoto L.Y., Shahab M., Souza R.T., 2017. Berry-cluster thinning to reduce compactness of 'Black Star' table grapes. Ciência Rural, 47, 1-7.

Schuermann D., Molinier J., Fritsch O., Barbara Hohn B., 2005. The dual nature of homologous recombination in plants. Trends Genet., 21, 172-181.

Scott K.D., Eggler P., Seaton G., Rossetto M., Ablett E.M., Lee L.S., Henry R.J., 2000. Analysis of SSRs derived from grape ESTs. Theor. Appl. Genet., 100, 723-726.

Sefc K.M., Lopes M.S., Lefort F., Botta R., Roubelakis-Angelakis K.A., Ibanez J., Pejic I., Wagner H.W., Glössl J., Steinkellner H., 2000. Microsatellite variability in grapevine cultivars from different European regions and evaluation of assignment testing to assess the geographic origin of cultivars. Theor. Appl. Genet., 100, 498-505.

Sefc K.M., Regner F., Turetschek E., Glössl J., Steinkellner H., 1999. Identification of microssatellite sequences in Vitis riparia and their applicability for genotyping of different Vitis species. Genome, 42, 367-373.

Sneath P.H., Sokal R.R., 1973. Numerical taxonomy: The principles and practice of numerical classification. San Francisco: Freeman, 573 p.

Snoussi H., Harbi Ben Slimane M., Ruiz-García L., MartínezZapater J.M., Arroyo-García R., 2004. Genetic relationship among cultivated and wild grapevine accessions from Tunisia. Genome, 47, 1211-1219.

Sousa J.S.I., 1996. Uvas para o Brasil. 791p. FEALQ, Piracicaba.

This P., Zapater J.M.M., Péros J-P., Lacombe T., 2011. Natural Variation in Vitis. In: Adam-Blondon A-F., Martinez-Zapater J-M., Kole C. (Eds.) Genetics, genomics and breeding of grapes, pp. 3063. Science Publishers, USA.

Thomas M.R., Cain P., Scott N.S., 1994. DNA typing of grapevines: a universal methodology and database for describing 
cultivars and evaluating genetic relatedness. Plant Mol. Biol., 25, 939-949.

Thomas M.R., Scott N.S., 1993. Microsatellites repeats in grapevine reveal DNA polymorphisms when analyzed as sequencetagged sites, STSs. Theor. Appl. Genet., 86, 985-990.
Walker A.R., Lee E., Bogs J., McDavid D.A.J., Thomas M.R., Robinson S.P., 2007. White grapes arose through the mutation of two similar and adjacent regulatory genes. Plant J., 49, 772-785.

Yeh F.C., Yang R., Boyle T., 1999. Popgene Version 1.31: Microsoft Window based freeware for population genetic analysis: Quick user guide. University of Albert, Center for International Forestry. 